\title{
FATORES ERGONÔMICOS E DE PSICOLOGIA AMBIENTAL QUE INTERFEREM NA REALIZAÇÃO DA TAREFA DE DENTISTAS E AUXILIARES
}

\author{
BORTOLUZZI, Thaize Vanessa Costa (1); \\ DE CARVALHO, Ramon Lima (2); \\ BINS ELY, Vera Helena Moro (3)
}

(1) Universidade Federal de Santa Catarina, Mestranda em Arquitetura e Urbanismo

e-mail:thaizebortoluzzi@gmail.com

(2) Universidade do Sul do Estado de Santa Catarina, Especialista em projeto de arquitetura sustentável: conservação racional de recursos naturais.

e-mail:contato@ramonlima.arq.br

(3) Universidade Federal de Santa Catarina, Doutora em Engenharia de Produção.

e-mail:vera.binsely@gmail.com

\begin{abstract}
RESUMO
O trabalho em consultório odontológico tem sido relacionado à doenças ocupacionais, principalmente as associadas à postura inadequada dos dentistas e auxiliares. O presente estudo analisou os fatores ergonômicos e de psicologia ambiental que podem interferir na realização das tarefas destes profissionais. Por meio da aplicação de instrumentos de Avaliação Pós Ocupação (APO), auxiliado por um guia para a prática saudável em odontologia, constatou-se aspectos positivos e negativos relativos as atividades praticadas e ao ambiente. Com os resultados obtidos foi possível sugerir diretrizes projetuais e recomendações ergonômicas que visam intensificar as potencialidades e qualificar as características indesejáveis.
\end{abstract}

Palavras chave: ergonomia; atendimento odontológico; consultório odontológico.

\begin{abstract}
Work in a dental practice has been related to occupational diseases, especially those associated with the inadequate posture of dentists and assistants. The present study analyzed the ergonomic and environmental psychology factors that may interfere in the accomplishment of the tasks of these professionals. Through the application of Post-Occupational Evaluation (POE) instruments, aided by a guide to healthy practice in dentistry, positive and negative aspects were observed regarding the activities performed and the environment. With the results obtained, it was possible to suggest projective guidelines and ergonomic recommendations to enhance the potential and qualify undesirable characteristics.
\end{abstract}

Keywords: ergonomics; dental care; dental office. 


\section{INTRODUÇÃO E JUSTIFICATIVA}

A prática das atividades odontológicas tem sido alvo de diversos estudos ergonômicos principalmente relacionados ao cirurgião-dentista devido à repetição dos esforços e as posturas específicas na realização das tarefas (YARID, 2009; GUPTA, 2014; RÉGIS FILHO; MICHELS; SELL, 2006). Trata-se de uma classe profissional com alto índice de desconforto e dores musculoesqueléticas com prevalência sugerida na literatura em torno de $64 \%$ e $93 \%$ (HAYES; COCKRELL; SMITH, 2009). Por consequência destacam-se os gastos com assistência médica, absenteísmo e indenizações, provenientes de motivos diversos, como degeneração dos discos intervertebrais, cefaleia, fadiga e varizes (YARD et al, 2009).

Como prováveis causas da dor e desconforto entre dentistas, são comumente apontadas as posturas de trabalho ergonomicamente inadequadas, provavelmente pelo conhecimento insuficiente de ergonomia, em conjunto com problemas do ambiente físico (RUNDCRANTZ, 1991). A maior ênfase no bem-estar do paciente durante o tratamento pode ser o principal motivo para a perda do foco na estação de trabalho e na realização das atividades do profissional (ORENHA, 2012).

Além dos fatores ergonômicos, os psicossociais do trabalho odontológico têm sido associados às desordens musculoesqueléticas. Na última década, evidências tem apontado que a pressão do tempo, as atividades repetitivas, a falta de controle, as altas demandas e um pobre suporte social, podem resultar em tensão e problemas musculoesqueléticos (LUNDBERG, 2002). Um estudo sobre os distúrbios na coluna cervical de dentistas comparou grupos de trabalhadores com e sem sintomas em relação a algumas variáveis psicossociais, tais como: ambiente de trabalho, harmonia pessoal e satisfação com a vida. Os dentistas que apresentavam problemas musculoesqueléticos reportaram menor satisfação no trabalho, maior ansiedade, qualidade de saúde inferior e menor confiança no futuro em comparação àqueles sem tais desordens (RUNDCRANTZ, 1991).

Além disso, Orenha et al. (2012) afirmam que número de mulheres dentistas vem crescendo na maioria dos países, sendo uma preocupação devido o sexo feminino estar mais propenso a uma maior variedade de dores musculares em comparação aos homens. Em geral, as mulheres são possivelmente mais afetadas por possuírem menor número de fibras musculares, menor capacidade de armazenar e converter glicogênio em energia útil e ainda questões relacionadas a jornada doméstica (COUTO, 2000).

Frente a esta realidade, o trabalho auxiliado por profissional qualificado vem sendo apontado positivamente na racionalização da tarefa do cirurgião dentista, refletindo na diminuição do desgaste físico e mental, permitindo sua concentração na solução do problema do paciente (BARROS, 1995). No entanto, o auxiliar do dentista também faz parte de um grupo exposto a uma grande variedade de problemas ocupacionais como as lesões por esforços repetitivos (LERs) e distúrbios osteomoleculares relacionados ao trabalho (DORTs). De acordo com Vieira e Segatto (2012) muitas das patologias que acometem os dentistas se estendem também a esta classe de trabalhadores.

Estudos têm demonstrado que proporcionar aos profissionais o conhecimento e as habilidades da ergonomia em adequar a estação de trabalho na realização das tarefas pode resultar na redução da taxa de lesões e dos custos associados a estas lesões (LEWIS et al, 2001). Dessa forma, o presente estudo - além de identificar e apresentar as inadequações posturais do dentista e seu auxiliar, com o intuito de assimilação e incorporação de posturas de trabalho saudáveis por parte destes profissionais - visa avaliar o comportamento humano e suas relações com o ambiente, apoiado em conhecimentos de psicologia ambiental. Por fim, pretende-se sugerir melhorias para o espaço físico no âmbito da arquitetura. 


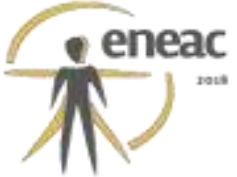

\section{MÉTODOS E TÉCNICAS}

\subsection{Trabalho de gabinete}

A partir do levantamento de referências teóricas publicadas por meios escritos ou eletrônicos, do estudo da Classificação Brasileira de Ocupações (CBO), da RDC 50 (ANVISA, 2002) e do Manual dos Serviços odontológicos elaborado pela ANVISA (2006), foi possível enriquecer o trabalho comparando a teoria com a prática exercida pelos profissionais envolvidos no estudo e, ainda, aprofundar-se em questões relacionadas aos aspectos do ambiente. Nesta etapa foi elaborado o cronograma das atividades a serem realizadas em campo e a criação dos instrumentos dos demais métodos.

\subsection{Trabalho de campo}

O primeiro contato dos pesquisadores com o objeto de estudo foram as visitas exploratórias. Neste momento foram realizados o levantamento físico-arquitetônico, registros fotográficos e a observação dos traços físicos, que teve por objetivo identificar o comportamento dos usuários no ambiente a partir de vestígios deixados pelas atividades realizadas. Utilizou-se o instrumento baseado nas quatro categorias desenvolvidas por Zeizel (2006). Elas subdividem-se em: 1) produtos de uso, relativos a como as pessoas utilizam os ambientes na realização das atividades; 2) adaptações ao uso, mudanças realizadas pelos usuários na adequação do ambiente às suas necessidades; 3) manifestações de identidade, que são vestígios de apropriação do espaço a partir da demarcação da identidade do usuário; 4) mensagens públicas, avisos deixados pelos usuários com o intuito de comunicação.

Na observação do comportamento, que ocorreu em dois dias e teve duração aproximada de 4 horas por participante, os pesquisadores adotaram a postura do tipo reconhecida, ou seja, os usuários estavam cientes sobre o tipo de estudo realizado no local. Buscou-se identificar as atividades exercidas e os relacionamentos necessários para sustentá-las, como a regularidade das atividades, forma de uso esperada do ambiente, novas formas de uso, usos indevidos e como o ambiente poderia gerar constrangimentos ou oportunidades (ZEISEL, 2006).

A fim de identificar os distúrbios musculoesqueléticos percebidos pelos trabalhadores do consultório avaliado (dentistas e auxiliar), utilizou-se o instrumento Questionário Nórdico (KUORINKA, 1987) uma técnica autoaplicável com múltiplas escolhas de identificação das ocorrências de constrangimentos físicos relacionados ao trabalho. Além das questões fechadas, o instrumento utiliza uma imagem de corpo humano como referência, onde os respondentes podem guiar-se para localizar as regiões anatômicas de seu corpo que apresentaram problemas nos últimos 7 dias, 12 meses e/ou se houve absenteísmo do trabalhador nos últimos 12 meses em função do problema.

A partir das entrevistas realizadas com os trabalhadores buscou-se conhecer a complexidade das tarefas exercidas e, também, a sua percepção em relação ao ambiente construído. Para tanto, foi utilizado um roteiro de entrevista do tipo semiestruturado, onde o entrevistador teve liberdade para desenvolver cada situação em qualquer direção que considere adequada dentro de uma conversa informal (MARCONI; LAKATOS, 2003).

O método Poema dos Desejos (SANOFF, 2001), foi utilizado com o intuito de investigar como seria o consultório odontológico ideal na percepção dos participantes. Trata-se de um método exploratório autoaplicável que permite ao respondente expressar, através de desenhos ou forma discursiva, seus anseios e imaginário a partir de uma frase préelaborada: "Eu gostaria que o consultório odontológico fosse ou tivesse..." 


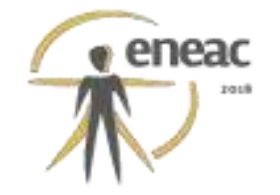

Para a análise dos dados qualitativos descritivos utilizou-se a técnica de análise de conteúdo e, especialmente para análise das observações do comportamento, utilizou-se o guia "Adopting a healthy sitting working posture during patient treatment", desenvolvido por Hokwerda (2006), que fornece informações para uma prática saudável da odontologia cuja teoria faz parte de um padrão internacional adotado pela Norma ISO/TC 106/SC 6 N 411.

\section{RESULTADOS E DISCUSSÃO}

\subsection{Objeto de estudo}

A sala do consultório odontológico faz parte de uma clínica multidisciplinar localizada em um edifício conhecido como um shopping de vizinhança, com atividades de compras e serviços. Além dos atendimentos realizados no consultório, que incluem as especialidades de endodontia, estética odontológica, clínica geral, e ortodontia, a clínica conta com a prestação de outros serviços especializados nas demais dependências, tais como: dermatologia, psicologia, fisioterapia, nutrição, entre outros.

A clínica, projetada por um escritório de arquitetura, recebeu contribuições dos proprietários tanto na definição do programa de necessidades quanto na atmosfera do espaço que gostariam de trabalhar. Dessa forma, nos ambientes voltados à interação social como a recepção e a sala de espera foram utilizados materiais como a madeira natural e o concreto aparente, evitando características rígidas e frias comumente encontradas nos consultórios odontológicos.

O local mede $6,26 \mathrm{~m}^{2}$ com pé direito de $2.46 \mathrm{~m}$. Quanto aos acabamentos, as paredes e o forro de gesso receberam pintura acrílica branca; o mobiliário odontológico, composto de mocho e cadeira de atendimento são em estrutura metálica na cor branca com estofamento revestido por tecido emborrachado próprio para ambientes de saúde. Os móveis sob medida são em chapa de madeira de média densidade nas cores branca e amadeirada com detalhes em vidro e espelho (figura 1) e a bancada de trabalho em pedra industrializada de alta resistência também na cor branca (figura 2).

A sala possui uma porta de acesso através do corredor interno da clínica e uma janela voltada para o leste com vista para o segundo bloco do edifício, de onde também é possível avistar montanhas mais ao fundo (figura 3). A luminária existente é do tipo de embutir com aletas de alumínio para a diminuição do ofuscamento. A sala possui condicionamento artificial do ar por aparelho Split.

Figura 1: Móvel amadeirado. Figura 2: Bancada de trabalho. Figura 3: Vista da janela.

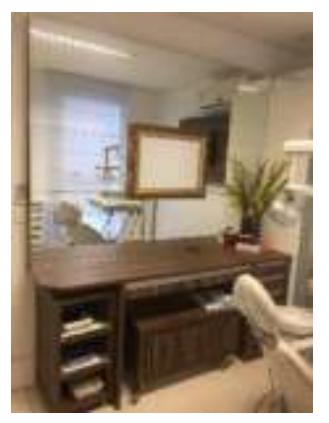

Fonte: os autores, 2017.

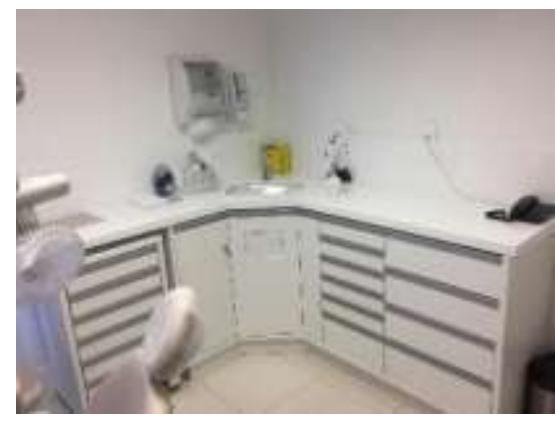

Fonte: os autores, 2017.

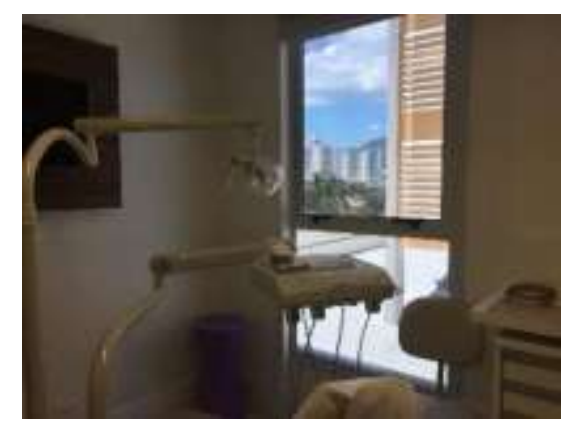

Fonte: os autores, 2017. 


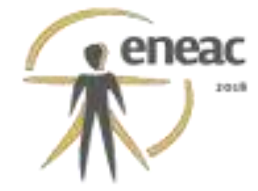

\subsection{Descrição dos usuários e das tarefas}

$\mathrm{Na}$ sala do consultório avaliado, revezam-se em dias alternados duas dentistas que atuam em diferentes especialidades, sendo que apenas uma delas recebe o auxílio de uma técnica em saúde bucal. Os dados demográficos dos trabalhadores bem como as informações relativas à atuação profissional encontram-se descritas na figura 4.

Figura 4: Dados dos participantes.

\begin{tabular}{|c|c|c|c|c|c|c|c|c|}
\hline Dados & Sexo & Idade & Altura & $\begin{array}{c}\text { hablidado } \\
\text { motora }\end{array}$ & Cargo & Especialidade & $\begin{array}{c}\text { Tempo de } \\
\text { atuaçóo }\end{array}$ & $\begin{array}{l}\text { jomoda de } \\
\text { trabalho }\end{array}$ \\
\hline Trabalhador 1 & Feminino & 43 & $1.67 \mathrm{~m}$ & Destra & Denfista & $\begin{array}{c}\text { Endodontia Estética } \\
\text { clinica geral }\end{array}$ & 20 anos & 8 horas \\
\hline Trabalhador 2 & Feminino & 34 & $1.70 \mathrm{~m}$ & Destra & Dentista & Ortodontia & 10 anos & 8 horas \\
\hline Trabalhador 3 & Forminino & 32 & $1.56 \mathrm{~m}$ & Destra & $\begin{array}{l}\text { Tecrico em } \\
\text { invide bucol }\end{array}$ & $x$ & 1.5 anos & 8 horas \\
\hline
\end{tabular}

Fonte: os autores, 2017.

A partir das entrevistas semiestruturadas com os trabalhadores e observação do comportamento foi possível verificar que as tarefas realizadas são condizentes com as prescritas no documento de classificação das profissões emitido pelo CBO. Os trabalhadores 1 e 2 atuam como dentistas na orientação e atendimento de pacientes adultos, já o trabalhador 3 organiza, faz a limpeza e esteriliza os materiais que serão utilizados nas consultas, e auxilia o dentista 1 e outros profissionais da clínica em procedimentos complexos.

Todos os participantes descreveram uma carga horária diária em torno de 8 horas. No entanto, o trabalhador 2 verbalizou que presta atendimento odontológico na clínica apenas 2 vezes por semana- nos demais dias atua em outras clínicas. O trabalhador 1 descreveu que dependendo do tipo de atendimento realizado, de acordo com o nível de complexidade, pode alterar sua jornada de trabalho, diminuindo a quantidade de consultas diárias em função do desgaste físico e mental.

O trabalhador 3, que ocupa entre outras funções a de auxiliar o profissional 1, descreveu que passa grande parte do dia em pé. Apenas este participante revelou que realiza pausas em horários pré-determinados, os demais o fazem, quando possível, entre um atendimento e outro. No entanto, nenhum dos participantes relatou que utiliza o intervalo para fazer algum tipo de alongamento.

Durante as observações percebeu-se um esforço das dentistas em posicionarem-se de forma a melhorar seu campo de visão e manuseio dos instrumentos em detrimento de uma postura adequada. De acordo com o guia desenvolvido por Hokwerda (2006), para que o profissional tenha uma postura saudável na realização da tarefa, ele deve manter-se ereto com a coluna relaxada, braços apoiados no corpo, tronco posicionado em um ângulo máximo de $20^{\circ}$ para frente, evitando a rotação do mesmo, com os braços em um ângulo máximo de $25^{\circ}$ para frente e $20^{\circ}$ para o lado. A posição ao sentar deve ser o mais próximo do encosto da cadeira a fim de favorecer um ângulo de $110^{\circ}$ das pernas levemente estendidas para frente em direção ao piso.

Os constrangimentos apontados pelo Questionário Nórdico identificaram a predominância de dores nos membros superiores das dentistas como pescoço e coluna lombar, e nos membros inferiores da técnica em saúde bucal, como pés, tornozelos e panturrilha. No entanto, não foram descritos absenteísmo em função dessas dores nos últimos 12 meses. 


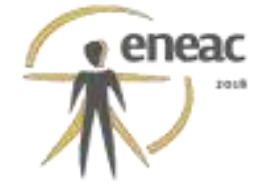

Ao cruzarem-se os dados obtidos pelo Questionário Nórdico e as observações realizadas pode- se perceber indícios da relação entre o tipo de atividade e a localização da dor (figura $5)$.

Figura 5: Resultados do questionário nórdico.

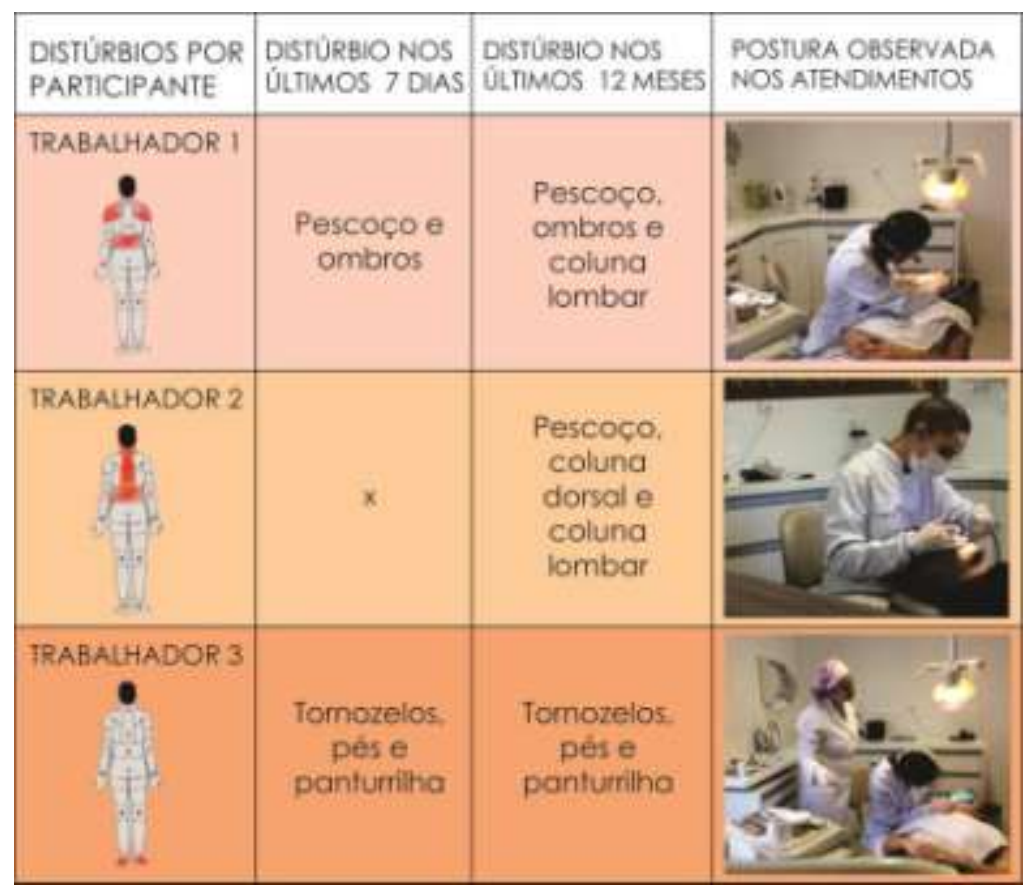

Fonte: os autores, 2017.

Os atendimentos na especialidade de endodontia e clínica geral realizados pela dentista 1 tiveram duração em torno de 1 hora cada, e envolveram grande esforço muscular principalmente quando se tratavam de procedimentos na arcada superior da boca do paciente, exigindo que a profissional mantivesse os braços longe do corpo, a coluna vertebral e o pescoço curvados, não atendendo as recomendações sugeridas pelo guia. Finsen et al. (1998) destacam que a área restrita da cavidade bucal do paciente exige invariabilidades posturais capazes de gerar condições insalubres de trabalho.

Os procedimentos de ortodontia executados pela dentista 2, tiveram em média 20 minutos de duração cada. Foram atendidos pacientes que receberam a manutenção do aparelho ortodôntico invisalign. Verificou-se, mesmo em procedimentos pouco invasivos como este, uma postura inadequada: a coluna vertebral e pescoço curvados, braços com abertura para fora excedendo o ângulo de $20^{\circ}$ e posição sentada longe do encosto da cadeira, que refletia num ângulo de pernas inferior a $110^{\circ}$. Apesar do esforço de aproximar-se ao máximo do campo visual, posicionando a cadeira odontológica na horizontal, o que é recomendado pelo guia, ao aproximar-se com o mocho, as pernas da dentista representavam um limitador, refletindo em uma postura não ergonômica. Houve o relato de diversas contraturas ao longo dos anos em decorrência da má postura na execução do trabalho aliada a excessos em exercícios físicos. Nessas situações foi recomendada pelo fisioterapeuta a realização de alongamentos entre um atendimento e outro, no entanto esta prática não é exercida pela dentista.

Verificou-se que quanto mais complexa for a tarefa, com maior esforço em acessar o campo de trabalho, envolvendo ainda a dor do paciente, maiores são as dificuldades em manter-se em uma postura saudável. Em relação às recomendações do guia, apenas o princípio 


\section{$\ddot{1}^{\text {eneac }}$}

expresso sobre o "trabalhar dinâmico", relacionado a realização de movimentos do corpo o tanto quanto forem possíveis a fim de que os músculos e a coluna vertebral recebam carga e relaxamento alternados, foi atendido.

Estudos revelaram significativas diferenças na forma de trabalhar dos dentistas com e sem dores musculoesqueléticas. Aqueles que apresentaram dor mantiveram a cabeça dobrada para o lado e giraram em maior extensão do que aqueles sem sintomas. $O$ uso de almofadas em ângulo pelos pacientes como forma de melhorar a visão direta da cavidade bucal pelo profissional durante 0 atendimento também foi apontada como um fator positivo, bem como a realização de pausas durante a jornada de trabalho (RUNDCRANZ; JOHNSSON; MORITZ, 1991).

Hokwerda (2006) afirmou que apesar da prática da odontologia de forma geral requerer esforço muscular para o atendimento ao paciente, os equipamentos empregados não estão sendo projetados ou construídos de forma a proporcionar ao dentista a oportunidade de trabalhar dentro de limites fisiológicos aceitáveis. Dessa forma justificam-se posturas inadequadas por não haver harmonia entre o equipamento e o dentista, impossibilitando a realização da tarefa de forma ergonômica.

Verificou-se durante as observações dos atendimentos de endodontia prestados pela dentista 1, gestos de tensão nas mãos e pés dos pacientes, gemidos e movimentos involuntários do corpo. Tais reações refletiram na atuação da profissional, que adotou uma postura curvada e inclinada a fim de acessar o melhor campo visual e proceder com 0 atendimento em menor tempo, buscando assim minimizar a exposição do paciente à dor.

Experimentos em laboratório apoiam a hipótese que as mesmas unidades motoras da região dos ombros e pescoço ativadas pelas demandas físicas também podem ser ativadas mentalmente, porém em baixa atividade. Portanto, uma atividade motora prolongada e a falta de descanso mental podem levar a um aumento da tensão nos músculos do pescoço e ombro, e gerar dor e desconforto, sintomas apontados pelo profissional 01 no Questionário Nórdico (LUNDBERG, 2002).

As tarefas exercidas pelo técnico em saúde bucal durante a observação foram: manuseio e preparo de soluções para o atendimento ao paciente, descarte de itens já utilizados, desinfecção da bancada, recolhimento de itens para a esterilização e auxílio do dentista 1 no atendimento aos pacientes. Observou-se que o profissional realizou suas tarefas em pé, o que parece ter relação com a dor nos pés e panturrilha descrita pelo profissional na ficha do Questionário Nórdico (figura 5).

Os resultados do Questionário Nórdico revelaram mais regiões de distúrbios musculoesqueléticos nas dentistas em comparação com a técnica em saúde bucal, o que vai ao encontro com um estudo de Lindfors (2006) realizado com mulheres que atuavam na

área da odontologia (dentistas e assistentes). A pesquisa revelou distúrbios musculoesqueléticos nas extremidades superiores do corpo relacionadas às características do trabalho em $81 \%$ das participantes, sendo que as dentistas relataram maiores níveis de carga física e fadiga se comparadas às assistentes.

\subsection{Ambiente}

A partir das respostas das entrevistas foi possível descobrir características do ambiente em relação à configuração ambiental, conforto e distrações positivas que podem estar interferindo na realização das tarefas. A planta baixa do consultório, representada pela figura 6, contém símbolos de mais "+" para aspectos positivos e menos "-“ para aspectos negativos verbalizados pelos participantes. 


\section{(x) $^{\text {reace }}$}

Figura 6: planta baixa do consultório com a identificação dos aspectos positivos e negativos apontados pelos trabalhadores.

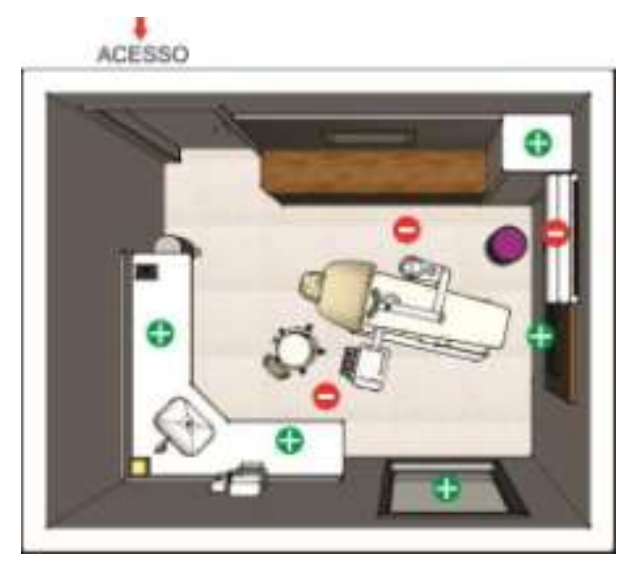

Fonte: os autores, 2017.

Dentre os aspectos positivos a bancada de trabalho que contém a pia para a lavagem das mãos foi mencionada por todos os participantes por sua disposição ao alcance das dentistas e pela diversidade das alturas das gavetas do balcão, capazes de armazenar os insumos, instrumentos e equipamentos de forma organizada. Vale destacar que o projeto das gavetas levou em consideração a dimensão de bandejas pré-fabricadas de plástico, com isto não houve desperdício de espaço evitando também a movimentação dos itens armazenados.

Ainda sobre a bancada, percebeu-se com a observação dos traços físicos características de adaptações de uso, tais como: a necessidade de apoiar itens de uso frequente sobre a bancada para otimizar o tempo de realização da tarefa; a disposição dos itens da dentista organizados próximos à cadeira odontológica e os de uso da auxiliar em direção a entrada do consultório com o intuito de melhorar o fluxo de trabalho e também a necessidade de dispor de pelo menor duas lixeiras, já que a presença uma lixeira embutida no balcão não supriu as necessidades de separação de lixo.

Não houve queixas em relação à altura da bancada de trabalho tampouco aos acabamentos que a compõe, no entanto, observou-se que o rodapé em chapa de madeira de média densidade estava danificado, possivelmente pelo contato com líquidos, configurando um traço físico de produto de uso. Portanto, nem todos os materiais se apresentaram em conformidade com a Norma RDC 50 (ANVISA, 2002) que recomenda o uso de acabamentos resistentes à lavagem e desinfecção.

Quanto às áreas livres, ambos os lados da cadeira odontológica receberam críticas pela falta de espaço. Na porção próxima à janela (lado direito da cadeira odontológica) há a presença do equipo e também de gavetas contendo insumos para o atendimento. No entanto, quando o equipo está em uso, não é possível realizar a aberturas das gavetas. Foi contabilizado a movimentação do equipo sete vezes durante um atendimento para que fosse possível realizar a abertura das gavetas. Já no lado esquerdo, a área livre para circulação é em torno de $46 \mathrm{~cm}$, considerada estreita para a passagem de pessoas.

O conflito observado na realização da tarefa em ambas as laterais da cadeira odontológica em função da falta de espaço é observada pelo manual da ANVISA (2006) em que a distância mínima livre nas laterais da cadeira odontológica deve ser de $1 \mathrm{~m}$, sendo que esta recomendação não foi atendida. Além disso, o consultório apresenta apenas $6,26 \mathrm{~m}^{2}$ de área enquanto que a área mínima recomendada para consultórios odontológicos individuais é $9,00 \mathrm{~m}^{2}$ (ANVISA, 2002). 


\section{$\ddot{1}^{\text {eneac }}$}

A presença de um assento extra para que um familiar acompanhe o atendimento do paciente foi verbalizada como positiva. No local existe uma banqueta de plástico, porém sua altura não é adequada, dificultando que os pés toquem o chão. A ausência de encosto também pode gerar desconforto, principalmente para um acompanhante idoso, obeso ou ainda quando o procedimento tem longa duração.

A falta de um sistema de chamada foi apontada como um fator negativo. Observou-se, em alguns procedimentos, a necessidade da presença da auxiliar. Neste momento a dentista interrompeu o atendimento e solicitou sua presença verbalmente através do corredor da clínica, contribuindo para a poluição sonora e troca de luvas da dentista, já que foi necessário tocar na maçaneta da porta.

Em relação ao conforto ambiental, destaca-se a posição da sala na fachada leste, que recebe apenas o sol da manhã, refletindo em uma temperatura agradável no decorrer do dia que dispensa muitas vezes o uso do condicionador artificial de ar. A posição da janela também foi avaliada como aspecto positivo pois proporciona luz natural na direção do paciente, contribui para a representação das cores e proporciona uma vista agradável para as montanhas (figura 3). Ademais, mesmo que as profissionais sejam destras não há sombreamento, uma vez que a luz artificial está posicionada sobre a cadeira do paciente.

Além da exposição dos profissionais aos ruídos emitidos pelos equipamentos, a sala recebe interferência dos sons do consultório ao lado. Apesar de não representarem um incômodo aos trabalhadores, acredita-se que em longo prazo isto possa colaborar para o aumento do estresse. No entanto, o trabalhador 3 verbalizou que o som ambiente da clínica ajuda a camuflar os ruídos e contribui para o relaxamento dos pacientes, promovendo maior sensação de acolhimento.

Outros aspectos observados pelos pesquisadores em desacordo com o manual da ANVISA (2006) são: rodapé saliente em relação à parede - o ideal seria a instalação do rodapé alinhado com a mesma; o aparelho de ar condicionado do tipo split não realiza a renovação do ar necessária para este tipo de estabelecimento, ele pode ser usado somente quando acompanhado por sistema de exaustão e/ou ventilação complementar, o que não foi verificado. Vale ressaltar que o posicionamento do aparelho split foi criticado pelos trabalhadores por sua localização na direção da cadeira odontológica refletindo na sensação de frio por pacientes e trabalhadores.

Em relação às distrações positivas, a cor branca nas paredes foi observada pelos participantes como adequada por ser neutra e não causar interferências na percepção da temperatura, ou mesmo no humor dos usuários. Foi mencionada a intenção de dispor de quadros nas paredes, e explicado que não foram instalados por haver outras prioridades estruturais a serem feitas na clínica. De acordo com os participantes a presença do aparelho de televisão é capaz de relaxar e distrair o paciente, entretanto ele não estava em funcionamento por algum problema técnico.

Os resultados do Poema dos Desejos revelaram que alguns aspectos ambientais existentes na sala são percebidos como ideais pelos trabalhadores, tais como: luz natural banhando a cadeira do paciente; ar condicionado; som ambiente; televisor e materiais e equipamentos dispostos próximo a cadeira do dentista. As demais características desejáveis mencionadas são: mocho confortável contribuindo para a posição da coluna ereta; consultório no andar térreo; maior contato com a natureza; aparelho para a chamada do auxiliar; maior espaço livre ao redor da cadeira odontológica e cadeira odontológica com elevação das pernas para maior conforto do paciente. 


\section{DIAGNÓSTICO E RECOMENDAÇÕES}

A partir do diagnóstico dos problemas que interferem na realização das tarefas, foi elaborado um quadro síntese de recomendações sugeridas pelos pesquisadores (Quadro 1).

\section{Quadro 1: diagnóstico e recomendações.}

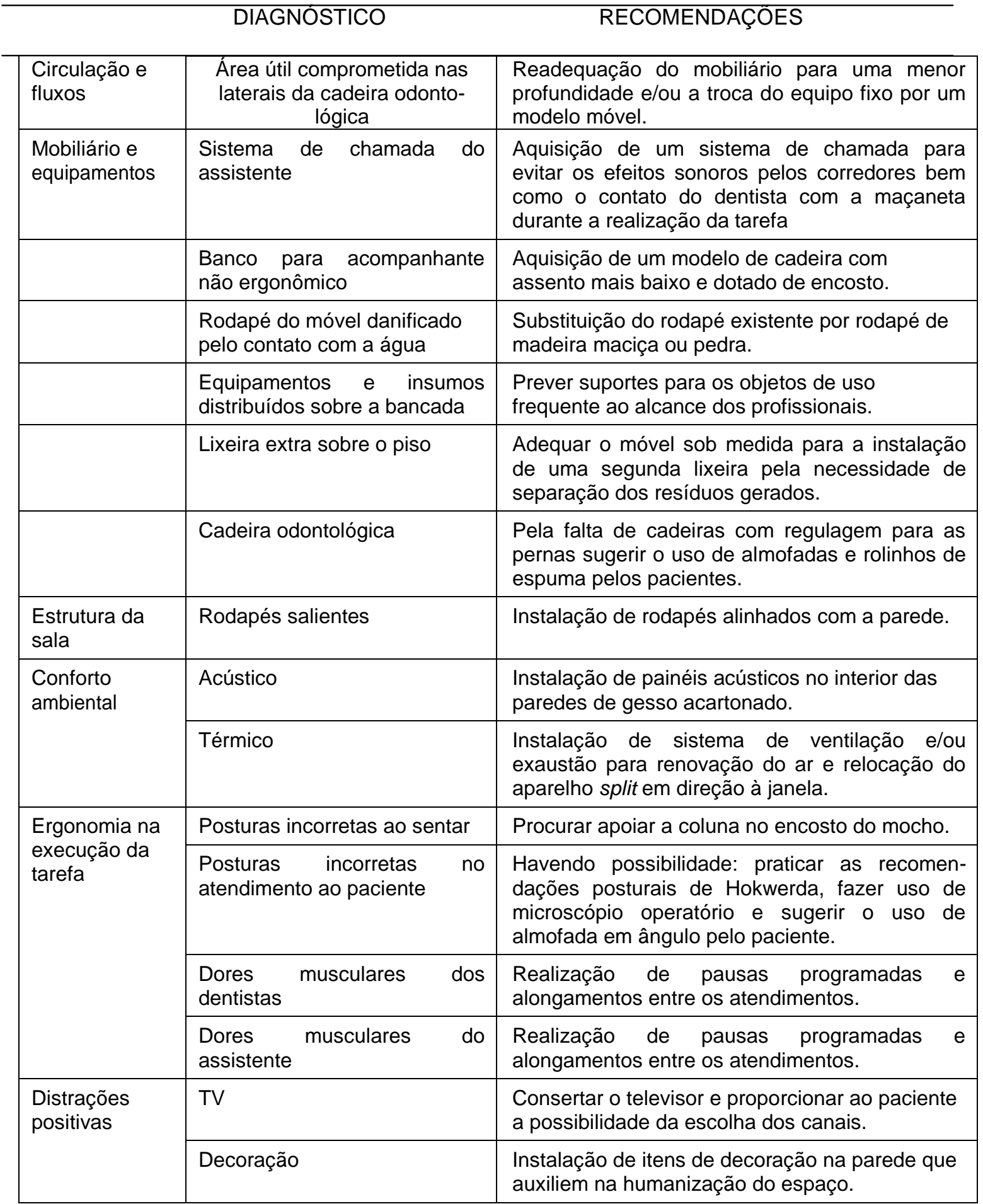




\section{(ame $^{\text {reme }}$}

\section{CONSIDERAÇÕES FINAIS}

Os resultados do estudo revelaram uma maior incidência de dores musculoesqueléticas nas dentistas em comparação com a assistente. Esses resultados são reflexos das demandas visuais, ações estáticas intercaladas com posturas inadequadas a que as dentistas estão sujeitas durante a realização das tarefas. Há ainda a exposição a vibrações e ruídos que contribuem para o desencadeamento do estresse e consequente aumento da carga muscular.

Nem sempre é possível atender às sugestões para uma prática saudável da odontologia especialmente pela dificuldade em acessar o campo visual ou manusear equipamentos na arcada dentária superior do paciente. Constatou-se que as dentistas se encontram propícias a desenvolver distúrbios musculoesqueléticos. É fundamental, portanto, a conscientização da importância da prevenção dos distúrbios adotando a prática de pausas durante a jornada de trabalho, posturas ergonômicas tanto quanto forem possíveis, e atividades físicas regulares.

A técnica em saúde bucal, que possui menor influência na execução e principalmente nas decisões do trabalho, apresentou dores relacionadas a prolongada postura em pé. No entanto, esta postura é essencial para auxílio do dentista, e sendo assim, alongamentos e pausas são indispensáveis para evitar complicações musculoesqueléticas.

Quanto aos aspectos ambientais verificou-se que a não concordância com a Norma RDC 50 (ANVISA, 2002) no que se refere as dimensões da sala e a falta de recirculação de ar podem trazer prejuízos no conforto ambiental e na realização das tarefas. É recomendável que pesquisas adicionais avaliem a ergonomia das posturas adotadas pelos dentistas de mesma especialidade, em consultórios semelhantes com a finalidade de aprofundar 0 debate e apresentar resultados que possam indicar se os distúrbios são provenientes das inadequações do posto de trabalho, da falta de ergonomia dos equipamentos ou de ambos.

\section{REFERÊNCIAS BIBLIOGRÁFICAS}

ANVISA - AGÊNCIA NACIONAL DE VIGILÂNCIA SANITÁRIA. Resolução RDC 50/2002.

Dispõe sobre o regulamento técnico para planejamento, programação, elaboração e avaliação de projetos físicos de Estabelecimentos Assistenciais de saúde. Brasília, 2002.

BARROS, O. B. Ergonomia III: auxiliares em odontologia ACD -THD - TPD - APD. São Paulo: Pancast; 1995.

BRASIL. Ministério do Trabalho e Emprego. Classificação Brasileira de Ocupações. Disponível em:<http://www.mtecbo.gov.br/cbosite/pages/home. jsf>, acesso em 12 dez. 2017.

BRASIL. Ministério da Saúde. Agência Nacional de Vigilância Sanitária. Serviços

Odontológicos: Prevenção e Controle de Riscos. Brasília: Ministério da Saúde, 2006.

COUTO, H. A. Novas perspectivas na abordagem preventiva das LER/DORT no Brasil. Belo Horizonte, 2000.

FINSEN, L; CHRISTENSEN, H; BAKKE, M. Musculoskeletal disorders among dentists and variation in dental work. Appl. Ergon.1998.

GUPTA, A. et al. Ergonomics in Dentistry. International Journal on Clinical Pediatric Dentistry, v.7, n.1, p. 30-34, 2014 


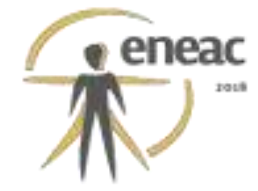

HAYES, M.; COCKRELL, D.; SMITH D. A. Systematic review of musculoskeletal disorders among dental professionals. Int. J. Dent. Hyg. V.7, n.3, p. 159-165, 2009.

HOKWERDA O; de RUIJTER R, SHAW S. Adopting a healthy sitting working posture during patient treatment. Optergo. July-2006. Available in:http://www.optergo.com/uk/images/Adopting. pdf. Accessed in: 27/11/2017

KUORINKA, I. et al. Standardized Nordic Questionnaires for the Analysis of Musculoskeletal symptoms. Applied Ergonomics, v. 18, n. 3, p. 233-37, 1987.

LINDFORS, P; THIELE, U; LUNDBERG, U. Work Characteristics and Upper Extremity Disorders in Female Dental Health Workers. Journal of occupational Health, v. 48, p. 192197, 2006.

LEWIS, R.J. et al. Musculoskeletal disorder worker compensation costs and injuries before and after an office ergonomics program. International journal of industrial ergonomics, v.29, n.2, p.95-99, 2001.

LUNDBERG, U. Psychophysiology of Work: Stress, Gender, Endocrine Response, and Work-Related Upper Extremity Disorders. American Journal of Industrial Medicine, v.41, p. 383-392, 2002.

MARCONI, M. A; LAKATOS, E. M. Fundamentos de metodologia científica. 5. Ed. São Paulo: Atlas, 2003.

ORENHA, E. S. et al. Assessment of ergonomic aspects in dental clinic rooms. Journal of Prevention Assessment \& Rehabilitation, v.41, p. 6103-6106, 2012.

RUNDECRANTZ, B. L. et al. Occupational cervico-branchial disorders among dentists.

Scand. J. Soc. Med, v. 19, n.3, 1991.

RÉGIS FILHO, G. I.; MICHELS, G.; SELL, I. Lesões por esforços repetitivos/distúrbios osteomusculares relacionados ao trabalho em cirurgiões-dentistas. Rev. Bras. Epidemiol. 2006.

YARID, S. D. et al. Aplicação de princípios de ergonomia no atendimento odontológico. Interbio, v.3, n.2, 2009.

SANOFF, H. School Building Assessment Methods. 2001.

ZEISEL, J. Inquiry by Design: Environmental/ Behavior/ Neuroscience in Architecture, Interiors, Landscape and Planning. New York, 2006. 